\title{
Dietary Fucose Affects Macrophage Polarization and Reproductive Performance in Mice
}

\author{
Ekaterina A. Litvinova ${ }^{1,2}$, Victoria D. Bets ${ }^{2,3}$, Natalya A. Feofanova ${ }^{1,4}$, Olga V. Gvozdeva ${ }^{2}$, \\ Kseniya M. Achasova ${ }^{1,2,5}$ (D), Elizaveta L. Alperina ${ }^{1}$ and Elena N. Kozhevnikova ${ }^{1,2,5, *}$ \\ 1 Scientific-Research Institute of Neurosciences and Medicine, 630117 Novosibirsk, Russia; \\ iph@physiol.ru (E.L.A.); info@niikim.ru (N.A.F.); info@mcb.nsc.ru (K.M.A.); e.l.alperina@physiol.ru (E.L.A.) \\ 2 Siberian Federal Scientific Centre of Agro-BioTechnologies of the Russian Academy of Sciences, Krasnoobsk, \\ 630501 Novosibirsk Region, Russia; rector@nsau.edu.ru (V.D.B.); so.prezidium@yandex.ru (O.V.G.) \\ 3 Faculty of Veterinary Medicine, Novosibirsk State Agrarian University, 630039 Novosibirsk, Russia \\ 4 Research Institute of Fundamental and Clinical Immunology, 630099 Novosibirsk, Russia \\ 5 Institute of Molecular and Cellular Biology, The Siberian Branch of the Russian Academy of Sciences, \\ 630090 Novosibirsk, Russia \\ * Correspondence: kozhevnikovaen@physiol.ru; Tel.: +7-383-373-0182
}

Citation: Litvinova, E.A.; Bets, V.D.; Feofanova, N.A.; Gvozdeva, O.V.; Achasova, K.M.; Alperina, E.L.; Kozhevnikova, E.N. Dietary Fucose Affects Macrophage Polarization and Reproductive Performance in Mice. Nutrients 2021, 13, 855. https:// doi.org/10.3390/nu13030855

Received: 22 February 2021

Accepted: 2 March 2021

Published: 5 March 2021

Publisher's Note: MDPI stays neutral with regard to jurisdictional claims in published maps and institutional affiliations.

Copyright: (c) 2021 by the authors. Licensee MDPI, Basel, Switzerland. This article is an open access article distributed under the terms and conditions of the Creative Commons Attribution (CC BY) license (https:/ / creativecommons.org/licenses/by/ $4.0 /)$.

\begin{abstract}
Intestinal mucus protects epithelial and immune cells from the gut resident microorganisms, and provides growth-promoting factors as mucus-derived O-glycans for beneficial bacteria. A lack of intestinal protective mucus results in changes in the commensal microflora composition, mucosal immune system reprogramming, and inflammation. Previous work has shown that fucose, the terminal glycan chain component of the intestinal glycoprotein Mucin2, and fucoidan polysaccharides have an anti-inflammatory effect in some mouse models of colitis. This study evaluates the effect of fucose on reproductive performance in heterozygous mutant $M u c 2$ female mice. We found that even though $\mathrm{Muc}^{+/-}$females are physiologically indistinguishable from C57Bl/6 mice, they have a significantly reduced reproductive performance upon dietary fucose supplementation. Metagenomic analysis reveals that the otherwise healthy wild-type siblings of $\mathrm{Muc}^{-/-}$animals have reduced numbers of some of the intestinal commensal bacterial species, compared to C57BL/ 6 mice. We propose that the changes in beneficial microflora affect the immune status in $\mathrm{Muc2}{ }^{+/-}$mice, which causes implantation impairment. In accordance with this hypothesis, we find that macrophage polarization during pregnancy is impaired in $\mathrm{Muc2}^{+/-}$females upon addition of fucose. Metabolic profiling of peritoneal macrophages from $\mathrm{Muc}^{+/-}$females reveals their predisposition towards anaerobic glycolysis in favor of oxidative phosphorylation, compared to C57BL/6-derived cells. In vitro experiments on phagocytosis activity and mitochondrial respiration suggest that fucose affects oxidative phosphorylation in a genotype-specific manner, which might interfere with implantation depending on the initial status of macrophages. This hypothesis is further confirmed in BALB/c female mice, where fucose caused pregnancy loss and opposed implantation-associated M2 macrophage polarization. Taken together, these data suggest that intestinal microflora affects host immunity and pregnancy outcome. At the same time, dietary fucose might act as a differential regulator of macrophage polarization during implantation, depending on the immune status of the host.
\end{abstract}

Keywords: Mucin 2; embryo implantation; fucose; macrophages; immune response; pregnancy

\section{Introduction}

The gastrointestinal (GI) microbiota is extensively involved in a variety of physiological processes, including the regulation of host metabolism, and immune function [1-8]. Its disruptions are linked to such disorders as obesity, atherosclerosis, diabetes, inflammatory bowel disease (IBD), colorectal cancer (CRC), and neurobehavioral abnormalities [4,7-9]. The gut microbiota plays an important role during pregnancy, which is associated with 
significant alterations in the host metabolism and immune system. Increasing evidence suggests that changes in the structure and function of the maternal intestinal microbiota may significantly affect pregnancy progression [7,10-12].

The inner intestinal surface is protected by the gel-like mucus produced by the specialized goblet cells and forms a physical barrier between the microorganisms and epithelial and immune cells $[13,14]$. Mucus is composed of heavily glycosylated proteins called mucins, among which Mucin 2 (MUC2) is the main secretory mucin in the small and large intestine [8,15-18]. The structural diversity and monosaccharide composition of MUC2 O-glycans have significant effects on mucus barrier function, the gut microbiome, and the immune status [8,15-17,19-21]. Mucin 2 (Muc2) gene knockout in mice results in immune cell reprogramming, carcinogenesis, and alterations in the gut microbiota [18,22-24]. Mice with the Muc2 deficiency showed clinical and morphological signs of colitis [18,24,25]. They developed intestinal and rectal tumors more frequently than the wild-type controls $[18,22,24]$. Increased susceptibility to experimental colitis and carcinomas have been also observed in mice lacking core 1- and core 3-derived O-glycans [26,27].

Generally, Muc2 knockout mice suffer from diarrhea, bloody stool, low weight, and tend to develop rectal prolapses by the age of 2-3 months. These factors have a strong negative impact on the course of pregnancy, so that most of the homozygous mutant females do not produce progeny $[28,29]$. Apparently, the physical condition of Muc2 knockout females prevents normal reproduction. However, the impact of microbiome, metabolism, and immune system alterations in pregnancy development cannot be excluded. It has been shown that the immune system was generally activated upon $M u c 2$ knockout, which might change the properties of the distinct immune cell types involved in pregnancy progression [30-32]. For instance, colitis is associated with altered gene expression profiles in macrophages that are involved in the maintenance of mucosal immune system homeostasis and prevent damaging inflammation [33-36]. Likewise, beneficial microbes are potential modulators of macrophage functions as a number of authors demonstrates that probiotics like Lactobacilli or microflora-derived metabolites like butyrate reduce inflammation and restore barrier function [28,37-40]. Thus, changes in metabolic profile and inflammatory signals associated with impaired microflora are key to macrophage polarization [41-44]. At the same time, macrophages assist pregnancy and undergo complex reprogramming during implantation [45-47]. M1 macrophages are found during early embryo development and embryo attachment, where M1/M2 transition occurs. M2 macrophages support placenta development and pregnancy maintenance. Macrophages re-polarize to M1 by the end of pregnancy and support parturition $[47,48]$. Therefore, intestinal inflammation and microflora imbalance during pregnancy might affect implantation and embryo development.

The major bacteria growth-promoting factors in the intestinal mucus-derived $\mathrm{O}$ glycans are often reduced upon colitis [21,49-51]. It is proposed that dietary glycans, like fucoidan, can partially substitute for the lack of the natural O-glycoside chains and have an ameliorating effect on inflammation and microflora composition [7,52-55]. However, to date, the impact of the external supplementation with mucus-derived glycans and their terminal monosaccharide fucose on pregnancy development remains unclear. Therefore, the aim of the present study was to evaluate the effect of fucose on pregnancy and reproductive performance in $\mathrm{C} 57 \mathrm{Bl} / 6, \mathrm{BALB} / \mathrm{c}$, and $\mathrm{Muc2}^{+/-}$mice that differ in immune status.

\section{Materials and Methods}

\subsection{Animal Housing}

The study was conducted in the Center for Genetic Resources of Laboratory Animals at the Federal Research Center Institute of Cytology and Genetics of The Siberian Branch of the Russian Academy of Sciences (ICG SB RAS), a unique identifier of the project RFMEFI62117 $\times 0015$. All procedures were conducted under Russian legislation according to Good Laboratory Practice standards (directive \# 267 from 19 June 2003 of the Ministry of Health of the Russian Federation), inter-institutional bioethical committee guidelines, and the European Convention for the protection of vertebrate animals used for experimental 
and other scientific purposes; all procedures were approved by the bioethical committee, protocol \#18.6 (14 October 2013). All animals used had specific pathogen free (SPF) status, which was tested quarterly according to FELASA recommendations [56].

The experiments were performed in adult male and female mice of the C57BL/6JNskrc (C57BL/6), $\mathrm{Muc2}^{+/-}$, and $\mathrm{Muc2}^{-/-}$strains. $\mathrm{Muc2^{+/- }}$ mice were generated by crossing $M u c 2^{\text {tm1 Avel }} / \mathrm{Muc}^{\text {tm1 Avel }}\left(\mathrm{Muc2}{ }^{-/-}\right.$on C57BL/ 6 genetic background) males to C57BL $/ 6 \mathrm{fe}-$ males. Muc2 $2^{-/}$mice were obtained from the Federal Research Centre "Fundamentals of Biotechnology" of the Russian Academy of Sciences (Moscow, Russia).

All animals were weaned at three weeks of age and kept in groups of same-sex siblings in open cages until 10-12 weeks. They were then placed in individually ventilated cages (outside cage dimensions: 13.5" (343 mm) L × 11.5" $(292 \mathrm{~mm}) \mathrm{W}$ (front) $\times 6.1^{\prime \prime}(155 \mathrm{~mm}) \mathrm{H}$; cage floor area: 75 square inches (484 square centimeters), Optimice (AnimalCare Systems, Centennial, USA. All animals were housed under a $14 \mathrm{~h} / 10 \mathrm{~h}$ light/dark photoperiod (light off at 16.00 ) with $22-24{ }^{\circ} \mathrm{C}$ temperature, $30-60 \%$ humidity, and 10 air changes per hour; food (ssniff Spezialdiaeten $\mathrm{GmbH}$, Soest, Germany) and water were provided ad libitum. Individually ventilated cages were supplied with birch sawdust as litter and plastic cups as shelter. Cages were replaced every 7 days, except for during the first $24 \mathrm{~h}$ after delivery. All samples were collected between 12:00 and 16:00 (light time period).

\subsection{Experimental Groups}

First mating. Female mice of each genotype (C57BL $/ 6, n=18$, and $\mathrm{Muc2}^{+/-}, n=18$ ) were placed in cages ( $n=3$ of the same genotype per cage, 12 cages in total). A mature male mouse (12-14 weeks old) was introduced into each cage with female mice for 4 days. C57BL/ 6 males were introduced to the C57BL/ 6 females, homozygous Muc2 mutant $\left(\mathrm{Muc2}^{-/-}\right)$males were introduced to $\mathrm{Muc2^{+/- }}$ females. After a male mouse was removed, each female was placed in an individual cage and randomly assigned to receive either regular drinking water ("Control" groups of C57BL/ 6 or $\mathrm{Muc}^{+/-}, n=9 /$ group), water with $0.05 \%$ fucose (Biosynth Carbosynth, Compton, UK) ("Fucose" groups of C57BL/ 6 or $\mathrm{Muc2}^{+/-}, n=9$ /group). The supplementation with fucose continued throughout.

Second mating. Two weeks after the pups weaning, the same $\mathrm{Muc2}^{+-}$female mice were placed in 12 cages ( $n=3$ per cage) with respect to the groups they were assigned in the first mating. A mature Muc2 heterozygous male mouse $\left(\mathrm{Muc2}^{+--}, 12-14\right.$ weeks old) was introduced into each cage with female mice for 2 days. After a male mouse was removed, the females were placed in individual cages and received water or monosaccharide solutions in the same concentration, so that each group received the same monosaccharide as it did in the first mating. The females were sacrificed and used for sample collection and reproductive system examination on the 12th day after removing a male mouse, gestation day (GD) 12-14.

Co-housing experiment. Three 5-6 weeks-old C57BL/ 6 female mice of each genotype were placed in the same cage with three 5-6 weeks-old $\mathrm{Muc}^{+/-}$female mice $(n=18$ in total for each genotype, making 6 cages in total) and-co-housed for 4 weeks. After that, females were separated according to their genotype and mated to male mice of the same genotype for 3 days. Then all female mice were placed back in the same cage in the same order (3 C57BL/ 6 and $3 \mathrm{Muc}^{+/-}$females), and co-housed until 17-19 d.p.c. After that, pregnant females were housed individually. On the day the male mice were removed, 18 female mice (3 cages) received $0.05 \%$ Fucose in drinking water until labor.

$\mathrm{BALB} / \mathrm{c}$ mating. Female mice of each genotype (C57BL/ $6, n=18$, and BALB/c, $n=18$ ) were placed in cages ( $n=3$ of the same genotype per cage, 12 cages in total). A mature male mouse (12-14 weeks old) was introduced into each cage with female mice for mating. C57BL/ 6 males were introduced to the C57BL/ 6 females, BALB/c males were introduced to BALB/c females. Females with vaginal plugs were placed in an individual cage and randomly assigned to receive either regular drinking water ("Control" groups of C57BL/ 6 or BALB/c, $n=9$ /group) or water with $0.05 \%$ fucose (Biosynth Carbosynth, UK) ("Fucose" groups of C57BL/ 6 or BALB/c, $n=9$ /group). The supplementation with fucose continued 
throughout pregnancy. Reproductive performance data for C57BL/6 mice was combined from the first mating and BALB/c mating.

\subsection{Sample and Tissue Collection}

Blood samples from the $\mathrm{Muc2^{+/- }}$ dams were collected by the orbital sinus puncture without using anesthesia as it can affect the immune cell count, due to glucocorticoid reaction $[57,58]$. For blood collection, the eyes of the test mice were treated with a drop of an ophthalmic anesthetic $(0.5 \%$ proparacaine hydrochloride ophthalmic solution, Alcon Laboratories, Camberley, UK). After blood collection, the mice were euthanized using $\mathrm{CO}_{2}$ inhalation. Immediately after, reproductive systems of $\mathrm{Muc}^{+/-}$dams were examined, embryos and yellow bodies were counted. Intestinal contents were collected from $\mathrm{Muc2}^{+/-}$ dams in a sterile $1.5-\mathrm{mL}$ plastic tube, snap-frozen in liquid nitrogen, and stored at $-70{ }^{\circ} \mathrm{C}$ until further analysis. For the macrophage isolation, separate matings were performed, the dams $(N=6-12)$ were sacrificed at $5 \mathrm{GD}$, and peritoneal macrophages were isolated. For this, females were euthanized by decapitation, and the peritoneal cavity was washed with $5 \mathrm{~mL}$ of sterile ice-cold PBS. Suspension of peritoneal cells was collected by a syringe and centrifuged for $5 \mathrm{~min}$ at $1500 \mathrm{rpm}$. Cell pellets were resuspended in DMEM medium with $10 \%$ FBS and left to adhere in 24-well culture plate (Corning) at $1 \times 10^{6}$ cells per well for $1 \mathrm{~h}$ in $\mathrm{CO}_{2}$ incubator at $37^{\circ} \mathrm{C}$. Non-adherent cells were removed by washing twice with PBS medium. Adherent macrophages were used for further assays. To test the effect of fucose on cellular metabolism and phagocytosis, each sample of peritoneal macrophages was divided into two wells and incubated with or without $0.1 \% \mathrm{~L}$-fucose for $12 \mathrm{~h}$. After that, cells were washed with medium without fucose and used for downstream applications.

\subsection{Metagenomic Analysis}

DNA was purified from intestinal contents using QIAamp DNA Stool Mini Kit (Qiagen, Hilden, Germany) according to the manufacturer's recommendations $(\mathrm{N}(\mathrm{C} 57 \mathrm{BL} / 6)=4$, $\left.\mathrm{N}\left(\mathrm{Muc}^{+/+}\right)=4\right)$. The $16 \mathrm{~S} r R N A 16 \mathrm{SV} 3-\mathrm{V} 4$ region was amplified using barcoded primers. All PCR reactions were carried out using Phusion ${ }^{\circledR}$ High-Fidelity PCR Master Mix (New England Biolabs, Ipswich, USA). PCR products was mixed in equal ratios. The mixture of PCR products were purified with Qiagen Gel Extraction Kit (Qiagen, Hilden, Germany). The libraries were generated with NEBNext ${ }^{\circledR}$ UltraTM DNA Library Prep Kit for Illumina and analyzed by the Illumina platform. Sequences analysis were performed by Uparse software. Sequences with $\geq 97 \%$ similarity were assigned to the same OTUs. Beta diversity analysis was used to evaluate differences between samples in species complexity. Beta diversity of both: Weighted and unweighted unifrac were calculated by QIIME software (Version 1.7.0). Cluster analysis was preceded by principal component analysis (PCA), which was applied to reduce the dimension of the original variables using the FactoMineR package and ggplot2 package in R software (Version 2.15.3). Normalized reads for each OUT were used to show the average top ten taxa in each group and calculate differences in taxa abundance between groups.

\subsection{Flow Cytometry Analysis (FC)}

Red blood cells were lysed with ammonium chloride buffer $\left(0.15 \mathrm{M} \mathrm{NH}_{4} \mathrm{Cl} ; 0.01 \mathrm{M}\right.$ $\mathrm{NaHCO}_{3} ; 0.001 \mathrm{M} \mathrm{EDTA}$ ) for $10 \mathrm{~min}$ at room temperature, and leukocytes were centrifuged at $1500 \mathrm{rpm}+4{ }^{\circ} \mathrm{C}$ for $5 \mathrm{~min}$. White blood cells were washed twice with $2 \%$ BSA in phosphate-buffered saline (PBS), resuspended in staining buffer (1\% BSA, $0.1 \%$ sodium azide in PBS), and diluted up to the concentration of 1000-1200 cells $/ \mu \mathrm{L}$. Then, $250 \mu \mathrm{L}$ of cell suspension were stained with PE-Cy7-CD45 (Rat IgG2b, k, clone 30-F11), FITC-

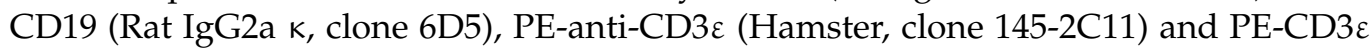
(Hamster, clone 145-2C11), FITC-CD4 (Rat IgG2b k, clone GK1.5), PE/Cy7-CD8a (Rat IgG2a $\kappa$, clone 53-6.7) anti-mouse antibodies (all BioLegend, San Diego, USA) for $120 \mathrm{~min}$ at $4{ }^{\circ} \mathrm{C}$ in the dark and then samples were analyzed using Guava easyCyte Flow Cytometer (Merck KGaA, Darmstadt, Germany). For analysis, 25,000 lymphocytes were counted 
in each sample. The number of blood $\mathrm{CD}^{+}$-and $\mathrm{CD} 8^{+}$-cells was expressed as a ratio of $\mathrm{CD}^{+}$- and $\mathrm{CD}^{+}$- percentages of $\mathrm{CD}^{+}$-cells. To determine leukocyte number, whole blood samples were stained with Türk's solution (Merck, USA), leukocytes were counted in a counting-chamber and expressed as $10^{\wedge} 6$ per $\mathrm{ml}$ of blood.

$250 \mu \mathrm{L}$ of macrophage cell suspension were stained with FITC-F4/80 (Rat IgG2b, k, clone EMR1), PE-CD209a (Mouse IgG2c, clone MMD3), APC-anti-CD86 (Rat IgG2a, clone GL-1) (all BioLegend, USA) for $60 \mathrm{~min}$ at $4{ }^{\circ} \mathrm{C}$ in the dark and then samples were analyzed using BD FACSCanto II Flow Cytometer. During analysis, we first isolated single cells (singlets), which were used to isolate macrophages positive for F4/80 marker. This cell population was further used to identify M1 (positive for CD86) and M2 macrophages (positive for CD209).

\subsection{Macrophage Phagocytosis Assay}

For in vitro phagocytosis, C57BL/ 6 and $M u c 2^{+/-}$dams were used ( $n=5$ for each genotype). Each macrophage preparation was divided into two samples and either incubated or not with $0.1 \%$ fucose for $12 \mathrm{~h}$. Two $\mu \mathrm{L}$ of fluorescent particle suspension (yellow-green latex beads $2-\mu \mathrm{m}$ in size, Sigma-Aldrich, St. Louis, USA) were added per each well of 24-well culture plate with adherent macrophages in final concentration $2 \mu \mathrm{L} / \mathrm{ml}$ media. Plates were placed or in $\mathrm{CO}_{2}$ incubator at $37^{\circ} \mathrm{C}$ for $1 \mathrm{~h}$. After that, media was removed, cells were washed 3 times with PBS, detached from the plate with a plastic scraper, resuspended in PBS, and used for flow cytometry analysis.

\subsection{Mitochondrial Respiration and Anaerobic Glycolysis}

Oxygen consumption rate (OCR) and extracellular acidification rate (ECAR) were measured using Seahorse XF Cell Mito Stress Test (Agilent, Santa Clara, CA, US). C57BL/6 $(n=5)$ and $\mathrm{Muc2}^{+/-}(n=6)$ dams were used for macrophage isolation. Each cell sample was divided into two and either incubated or not with $0.1 \%$ fucose for $12 \mathrm{~h}$. After that, cells were seeded onto an XFe24 bioflux plate (Seahorse Bioscience, North Billerica, USA) at a pre-optimized final concentration of $5 \times 10^{5}$ cells/well. Mitochondrial function was measured as OCR after injections of $0.5 \mu \mathrm{M}$ oligomycin (ATP synthase inhibitor), $1 \mu \mathrm{M}$ FCCP (electron transport chain accelerator), and $1 \mu \mathrm{M}$ anti-mycin A (complex III inhibitor) plus $1 \mu \mathrm{M}$ rotenone (complex I inhibitor), according to the manufacturer's instructions. ECAR was measured simultaneously in the same experiment. Seahorse XFe Wave Software (Seahorse Bioscience, North Billerica, USA) was applied to analyze the data.

\subsection{Data Analysis and Statistics}

The data were tested for normality using the Kolmogorov-Smirnov test. Normally distributed data were processed using analysis of variance (ANOVA) and Student's $t$ test test. Not normally distributed data were processed using Mann-Whitney $U$ test. Ln-transformation was applied to macrophage percentages and SeaHorse analysis data, followed by the Kolmogorov-Smirnov test prior to ANOVA. Reproductive performance, pre-implantation losses, and post-implantation losses were analyzed using Fisher exact test. In vitro phagocytosis and mitochondrial respiration were analyzed using paired Student's $t$-test.

\section{Results}

\subsection{The Effect of Fucose on Reproductive Performance of $\mathrm{Muc} 2^{+/-}$and C57BL/6 Females}

As $M u c 2$ homozygous mutant females do not produce progeny, we aimed to overcome this issue by adding fucose to the drinking water, but revealed no positive effect (data not shown). However, we noticed that $\mathrm{Muc}^{+/-}$females routinely used to maintain mutant mouse colony did not produce progeny upon the same treatment. Thus, we first evaluated the effect of monosaccharide fucose on the reproductive performance of the $M u c 2^{+/-}$ females. We found that fucose decreased reproductive performance of test females crossed 
to $\mathrm{Muc}^{2-}$ males (first mating). The addition of fucose resulted in no offspring ( $23 \mathrm{vs.} 0$, Fisher exact test $p<0.001$, Figure 1A).

\section{A Reproductive performance A' Reproductive performance upon co-housing}

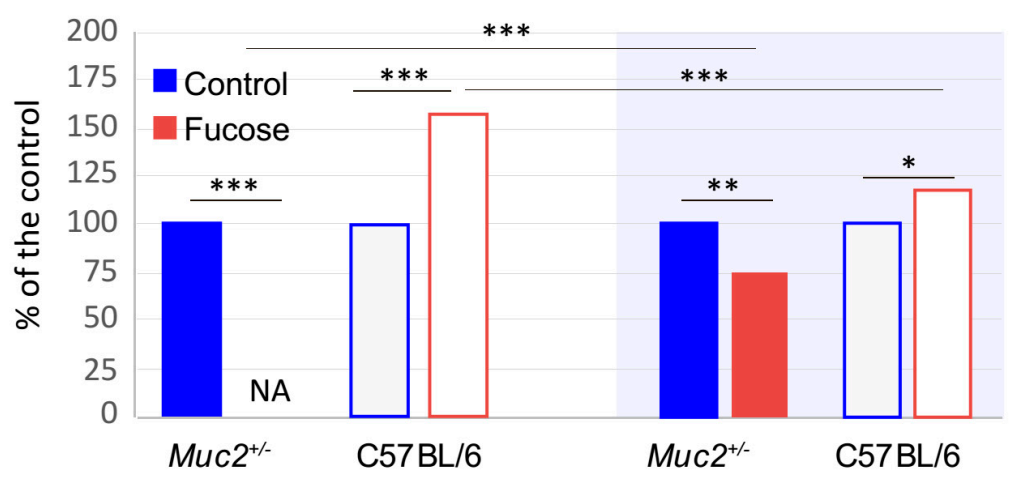

\section{B Pre- and post-implantation losses}

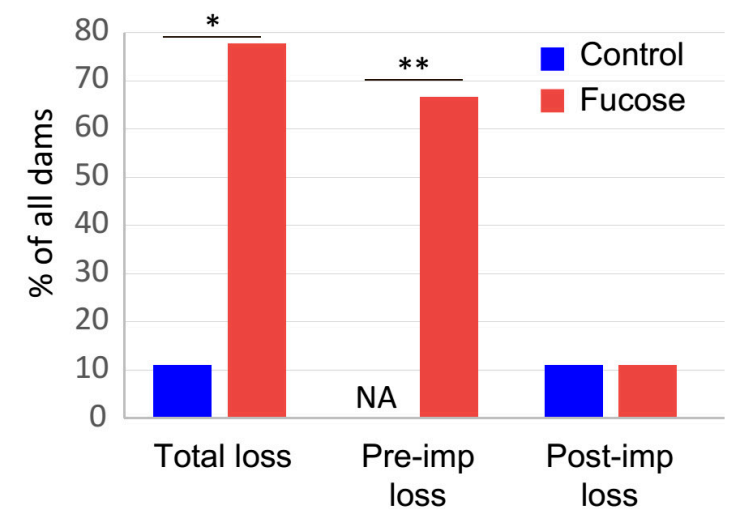

C
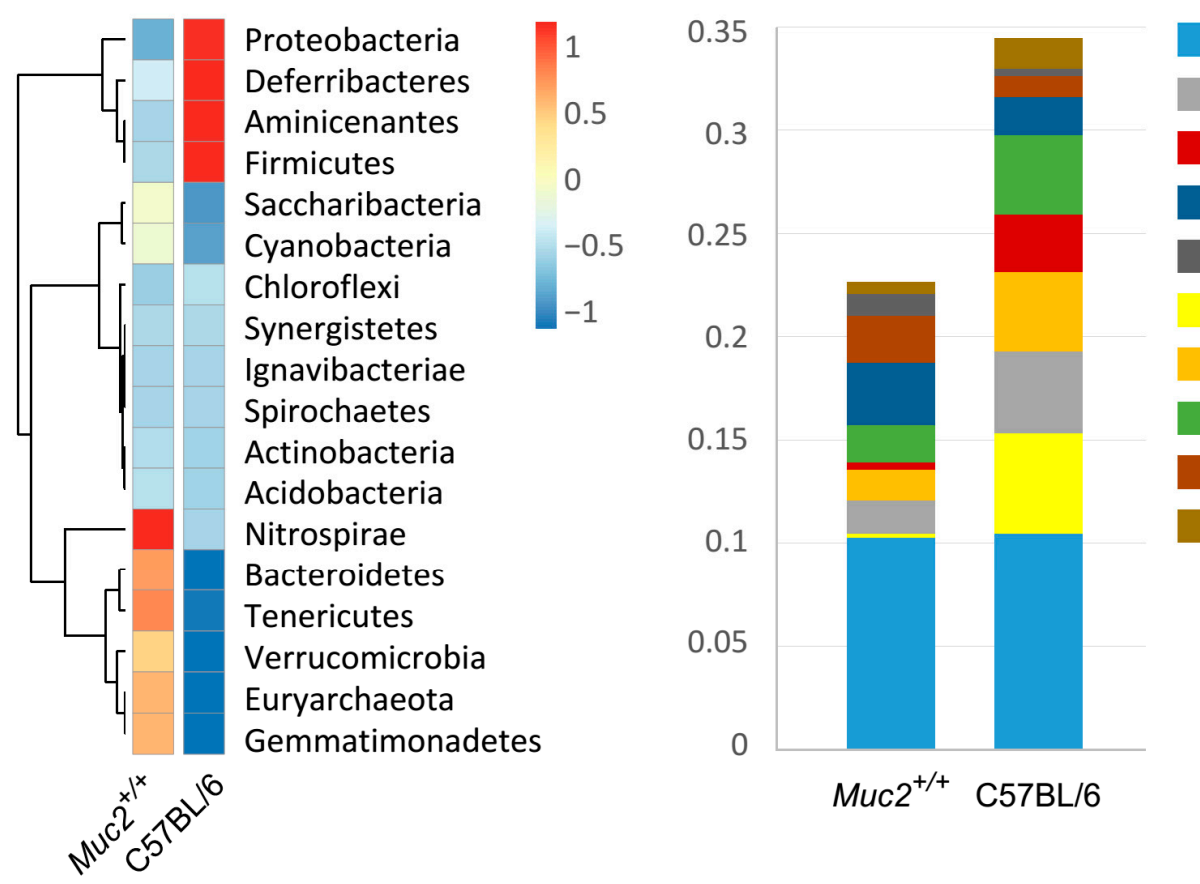

Lachnospiraceae_NK4A136

Bacteroides

Blautia

_ Prevotellaceae_UCG-001

Anaeroplasma

Escherichia-Shigella

Alistipes

Alloprevotella

Akkermansia

Lachnoclostridium

Figure 1. Fucose affects reproductive performance in $\mathrm{Muc2}^{+/-}$and C57BL/6 dams. (A). Reproductive performance in $9 \mathrm{Muc2}^{+/-} \times{\sigma^{\top}}^{\mathrm{M}} \mathrm{Muc} 2^{-/-}$and in C57BL/6 matings. ${ }^{* * *} p<0.001$, Fisher exact test; $\mathrm{N}\left(\mathrm{Muc} 2^{+/-} \mathrm{dams}\right)=9$, $\mathrm{N}($ C57BL $/ 6$ dams $)=18$. (A'). Reproductive performance of $\mathrm{Muc}^{+/-}$and C57BL/6 female mice upon co-housing. ${ }^{*} p<0.05$, ${ }^{* *} p<0.01,{ }^{* * *} p<0.001$, Fisher exact test; $\mathrm{N}\left(\mathrm{Muc2}^{+/-}\right.$dams $)=9, \mathrm{~N}(\mathrm{C} 57 \mathrm{BL} / 6$ dams $)=9$ in each group. (B). Pre- and postimplantation losses in in $\$ M u c 2^{+/-} \mathrm{x} 0^{\top} \mathrm{Muc2}^{+/-}$matings. "Fucose" vs. "Control": ${ }^{*} p<0.05,{ }^{* *} p<0.01,{ }^{* * *} p<0.001$, Fisher exact test; $\mathrm{N}($ dams $)=9$ in each group. (C). Cluster analysis of OTU in Muc2 ${ }^{+/+}(\mathrm{N}=4)$ and C57BL/6 $(\mathrm{N}=4)$ animals. (D). Percent of top 10 OTU present in the intestinal content.

We further tested whether this effect was exclusive to the females of $\mathrm{Muc2}^{+/-}$genotype. Therefore, we supplemented the drinking water of C57BL/ 6 females with fucose, along with the control group that received drinking water. On the contrary, the reproductive performance of the C57BL/ 6 females was significantly higher upon fucose treatment as compared to the untreated control (Fisher exact test, $p<0.001$, Figure 1A). This data 
demonstrates that the effect of fucose was opposite in the two groups and depended on the genotype.

We then questioned which state of pregnancy was affected by the fucose. In order to exclude the effect of germ-line deficiency in $\mathrm{Muc}^{-/-}$males, we used $\mathrm{Muc2}^{+/-}$males in the second mating with the $M u c 2^{+/-}$females. We scarified dams $(\mathrm{N}=9)$ in the second mating on the 12-14 d.p.c. to count embryos and yellow bodies. We found that fucose elevated pre-implantation losses: All females in the "Fucose" group had yellow bodies, but only 3 out of 9 females had any embryos upon fucose treatment in comparison to the control group, where all of the nine females with yellow bodies had at least one embryo (Fisher exact test, $p<0.01$, Figure 1B). Post-implantation losses were insignificant in the "Fucose" group, but total losses were higher in this group as compared to the control (Fisher exact test, $p<0.05$, Figure 1B).

It was shown previously that $\mathrm{Muc}^{+/-}$animals are physiologically healthy and cannot be distinguished from C57BL/ 6 based on intestinal morphology and inflammatory parameters [59]. However, these animals were co-housed with their mutant littermates and might have microflora shifts associated with Muc2 mutation as it was shown that co-housing can affect microbiome [60]. Thus, we performed a metagenomic analysis of the intestinal microbiome of wild-type littermates co-housed with Muc2 mutant mice and C57BL/6 animals housed separately in individually ventilated cages. We found that, indeed, co-housing with Muc2 mutant mice affected the microbiome of their wild-type littermates compared to C57BL/6 (Figure 1C). For instance, Blautia and Escherichia species were significantly reduced upon co-housing with $M u c 2$ mutants as revealed by a Mann-Whitney $U$ test ( $Z=2.16, p<0.05$ for both). Thus, the deficiency in beneficial microbes might contribute to the effect of fucose on pregnancy in $\mathrm{Muc2}^{+/-}$dams.

To confirm the effect of microflora on reproduction in $\mathrm{Muc2}^{+/-}$animals, we co-housed $\mathrm{Muc2}^{+/}$and C57BL/ 6 female mice before and during pregnancy. We found that co-housing with C57BL/ 6 mice significantly increased reproductive performance in $M u c 2^{+/-}$dams after fucose treatment (Fisher exact test, $p<0.001$, Figure $1 \mathrm{~A}, \mathrm{~A}^{\prime}$ ); however, it did not completely restore it (Fisher exact test, $p<0.01$, Figure $1 \mathrm{~A}^{\prime}$ ). At the same time, co-housing C57BL/ 6 dams with $M u c 2^{+/-}$mice attenuated the beneficiary effect of fucose on pregnancy (Fisher exact test, $p<0.001$, Figure $1 \mathrm{~A}, \mathrm{~A}^{\prime}$ ), though it was not fully eliminated (Fisher exact test, $p<0.05$, Figure $\left.1 \mathrm{~A}^{\prime}\right)$. Together this data shows that equilibration of microflora between $\mathrm{Muc2}^{+/-}$and C57BL/ 6 dams by co-housing mitigates the differences in their reproductive performance. It confirms our hypothesis that the reported above reproductive failure of $\mathrm{Muc}^{+/-}$dams upon fucose treatment originates from the microbiome composition of these otherwise healthy animals.

\subsection{The Effect of Fucose on the Systemic Immune Response}

An appropriate and balanced immune reaction is important for successful implantation and embryo development during pregnancy [61]. As intestinal bacteria do not directly affect embryo development and implantation, we questioned whether microflora might affect pregnancy via modulation of the immune system. To test this hypothesis, we used FC analysis that quantifies the major lymphocyte populations in the blood: Tcells $\left(\mathrm{CD} 45^{+} \mathrm{CD}^{+}\right)$and B-cells $\left(\mathrm{CD} 45^{+} \mathrm{CD} 19^{+}\right)$and subpopulations of T-cells: T-helpers $\left(\mathrm{CD}^{+} \mathrm{CD}^{+}\right)$and T-killers $\left(\mathrm{CD}^{+} \mathrm{CD}^{+}\right)$. FC did not reveal any effects of the monosaccharide on the total count of leukocytes, the absolute numbers of $\mathrm{CD} 45^{+} \mathrm{CD} 3^{+}$and $\mathrm{CD} 3^{+} \mathrm{CD} 4^{+}$, the percentages of $\mathrm{CD}^{+} \mathrm{CD}^{+}$and $\mathrm{CD}^{+} \mathrm{CD}^{+}$, and the percentage ratio of $\mathrm{CD}^{+} \mathrm{CD}^{+}$to $\mathrm{CD}^{+} \mathrm{CD}^{+}$lymphocytes (Figure $2 \mathrm{~A}$ ). However, there was a strong effect of fucose on the percentage ratio of T-cells to B-cells. Fucose significantly reduced the CD3/CD19 percentage ratio as compared to the "Control" (Student's $t$-test: "Fucose": $p=0.001$ ). Fucose also significantly reduced the absolute numbers of $\mathrm{CD} 45^{+} \mathrm{CD}^{+}, \mathrm{CD}^{+} \mathrm{CD}^{+}$, and $\mathrm{CD} 3^{+} \mathrm{CD} 4^{+}$ (Student's $t$-test: "Fucose": $p<0.05$ for each cell type) lymphocytes, and the percentage of $\mathrm{CD}{ }^{+} \mathrm{CD}^{+}$lymphocytes (Student's $t$-test: "Fucose": $p<0.01$, Figure $2 \mathrm{~A}$ ). At the same time, 
fucose treatment resulted in a significant increase of $\mathrm{CD} 45^{+} \mathrm{CD} 19^{+}$lymphocytes percentage (Student's $t$-test: "Fucose": $p<0.001$ ).

A Blood immune cells, Muc2+-- dams, 12-14 GD
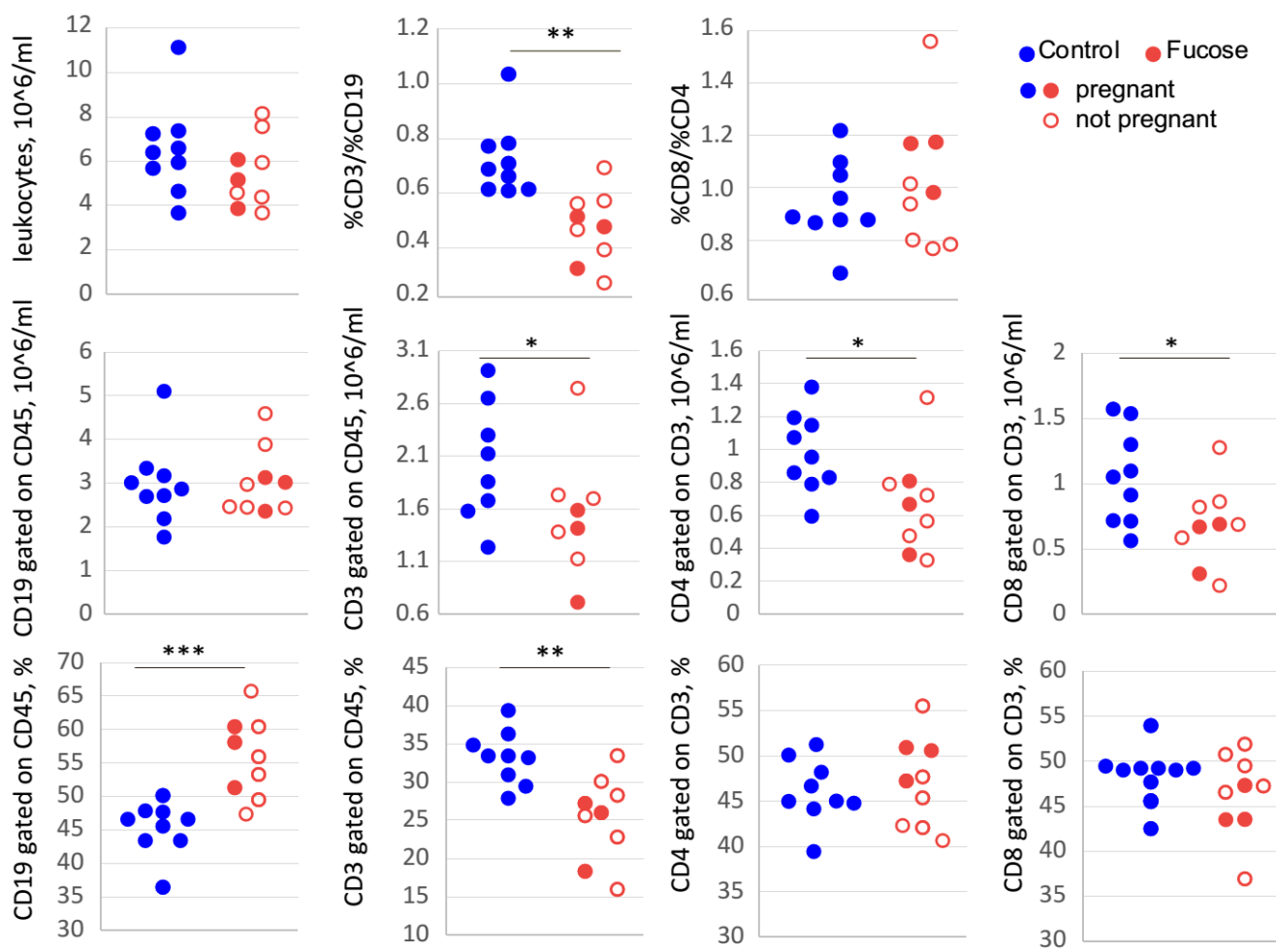

B Gating strategy for peritoneal macrophage polarization analysis
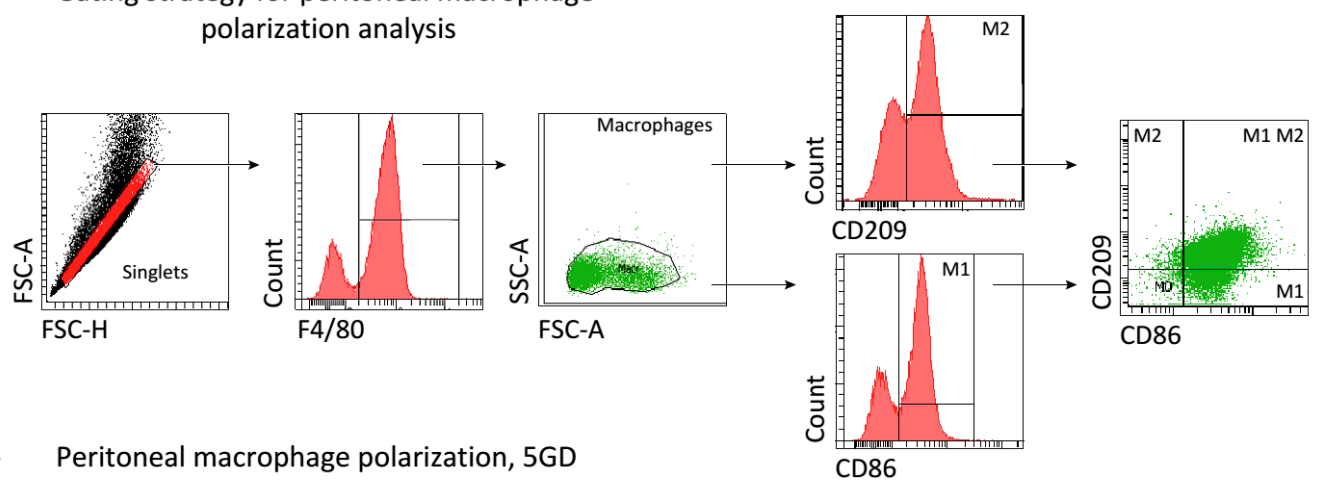

C

Peritoneal macrophage polarization, 5GD
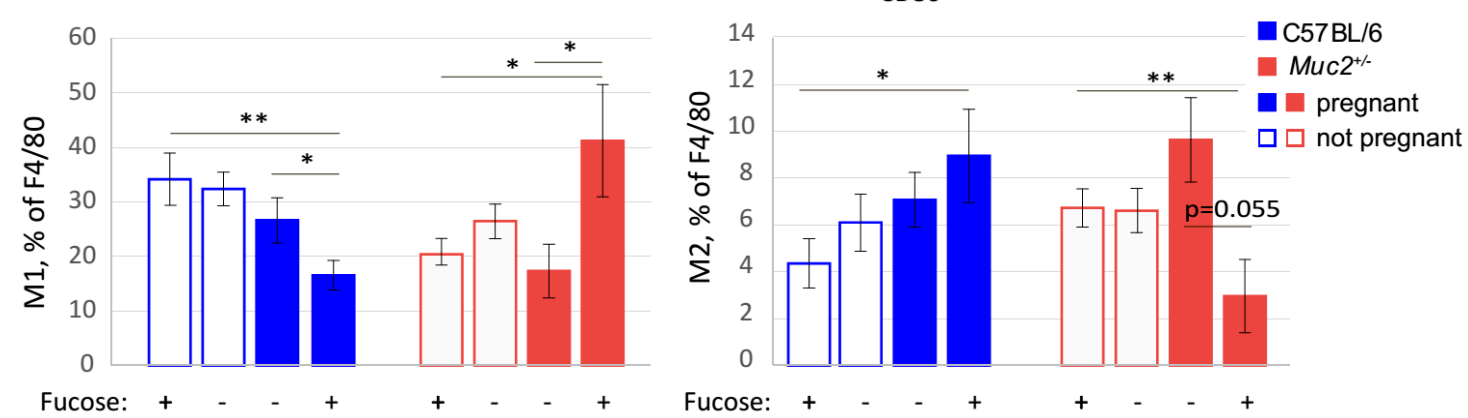

Figure 2. Blood immune cells ratios in $\mathrm{Muc}^{+/-}$dams and peritoneal macrophage polarization in C57BL/6 and $\mathrm{Muc2^{+/- }}$ dams. (A). Blood immune cells: Absolute numbers, percentages, and percentage ratios. "Fucose" vs. "Control": ${ }^{*} p<0.05$, ${ }^{* *} p<0.01,{ }^{* * *} p<0.001$; Student's $t$-test, $\mathrm{N}($ dams $)=9$ in all groups. (B). Gating strategy for peritoneal macrophage polarization analysis. (C). Percentage of M1 and M2 macrophages with and without fucose treatment in C57BL/6 and $\mathrm{Muc2}^{+/-}$dams.: ${ }^{*} p<0.05,{ }^{* *} p<0.01, \mathrm{~N}=6-10$ in each group, Student's $t$-test. 
These data demonstrate that fucose affects major blood lymphocyte populations. Therefore, it might also influence other immune cell types involved in implantation and pregnancy. Since macrophages are well known to provide regulatory signals during implantation, we tested the effect of fucose on the polarization of peritoneal macrophages from $\mathrm{Muc2}^{+/-}$and C57BL/ 6 female mice. Pregnant and non-pregnant dams of both genotypes at 5GD with and without fucose treatment were used ( $n=6-10$ in each group, eight groups in total). There was a significant interaction of "Genotype", "Pregnancy" and "Fucose" factors for M1 $(\mathrm{F}(1,59)=12.19, p<0.001)$ and M2 (F $(1,59)=9.11, p<0.001)$ macrophage percentages. After fucose treatment, the percentage of M1 macrophages in C57BL/ 6 pregnant dams was significantly lower as compared to non-pregnant females (Student's $t$-test: $p<0.01$, Figure 2C ). In pregnant C57BL/ 6 dams, the percentage of M1 macrophages were lower after fucose treatment (Student's t-test: $p<0.05$, Figure 2C). On the contrary, after fucose treatment, the percentage of M1 macrophages in $\mathrm{Muc}^{+/-}$ pregnant dams was significantly higher as compared to non-pregnant females (Student's $t$-test: $p<0.05$, Figure 2C). In pregnant $\mathrm{Muc}^{+/-}$dams, the percentage of M1 macrophages were higher after fucose treatment (Student's $t$-test: $p<0.05$, Figure 2C). Fucose also exerted an opposing effect on M2 macrophages in the two genotypes. After fucose, the percentage of M2 macrophages increased upon pregnancy in C57BL/ 6 dams (Student's $t$-test: $p<0.05$, Figure 2C), but decreased in $M u 2^{+/-}$dams (Student's t-test: $p<0.05$, Figure 2C). In pregnant $\mathrm{Muc2}^{+/-}$dams, there was a tendency for M2 decrease after fucose treatment (Student's $t$-test: $p=0.055$, Figure 2C). These data indicate that fucose affects T- to B-cell ratio and opposes M2 polarization in $\mathrm{Muc2}^{+-}$dams, which might contribute to the local immune reactions in the uterus and placenta.

\subsection{Fucose Regulates Macrophage Activity and Metabolism In Vitro}

The effect of fucose on reproduction and macrophage polarization might be either direct or indirect, for instance, via modulation of the microbiome. We used in vitro experiments with primary peritoneal macrophages to understand whether fucose can directly regulate their properties. Metabolic changes accompany macrophage polarization, and might predispose their fate. Thus, we investigated oxidative phosphorylation and anaerobic glycolysis-metabolic signatures of M2/M1 polarization in macrophages isolated from C57BL/6 $(n=5)$ and $\mathrm{Muc2}^{+-}(n=6)$ dams upon addition of fucose in vitro. We found that fucose generally reduced OCR in C57BL/6-derived macrophages, but this effect was not statistically significant (Figure $3 \mathrm{~A}$ ). At the same time, ANOVA revealed a significant effect of genotype on basal respiration $(\mathrm{F}(1,18)=5.7 p<0.05)$, maximal respiratory capacity $(\mathrm{F}(1,18)=3,3 p<0.01)$, reserved respiratory capacity $(\mathrm{F}(1,18)=2.5 p<0.01)$ and glycolytic capacity $(\mathrm{F}(1,18)=18.8, p=0.001)$. Oxidative phosphorylation was more prominent in C57BL/6-derived macrophages as basal respiration, maximal, and reserved respiratory capacity were higher in this group (Student's $t$-test: $p<0.05, p<0.01$, and $p=0.01$, respectively, Figure $3 \mathrm{~B})$. On the contrary, glycolytic capacity was significantly higher in $M u c 2^{+/-}$-derived cells (Student's $t$-test: $p<0.05$, Figure 3C,D). This experiment shows that the metabolic states of macrophages are different in the two genotypes. However, fucose is unable to change these parameters in vitro. We also performed in vitro phagocytosis as a functional test for macrophages from C57BL/6 $(n=5)$ and $\mathrm{Muc2}^{+/-}(n=5)$ dams. Twelve hour-long incubation with fucose significantly increased their phagocytosis activity (paired Student's $t$-test, $p<0,05$ for each, Figure 3E), but did not have any genotype-specific effect. Thus, at least in part, fucose might directly regulate macrophage function. 
A

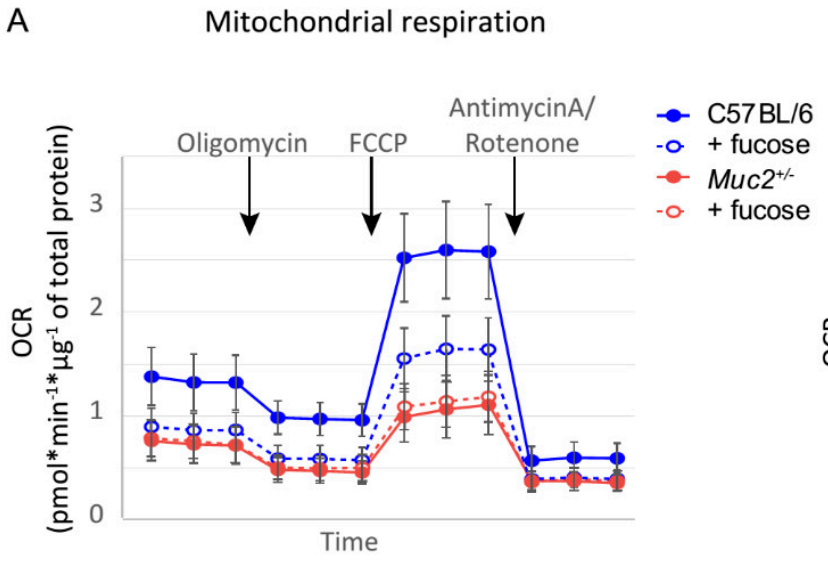

B Mitochondrial respiration

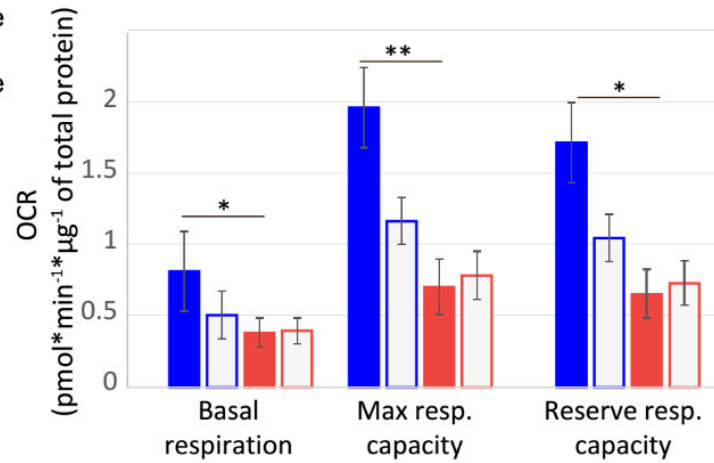

C

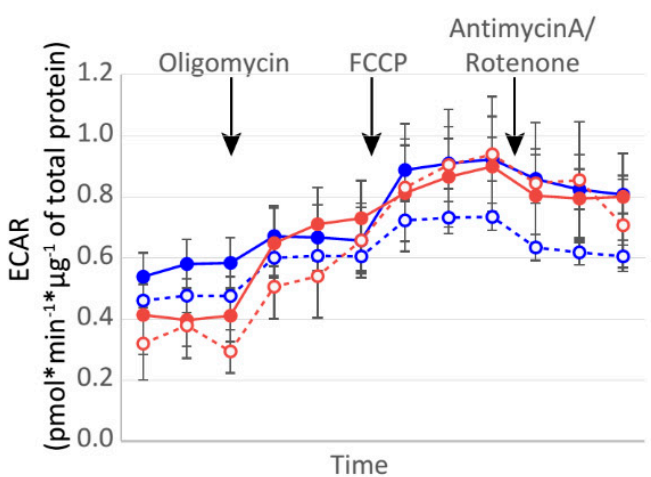

D Anaerobic glycolysis

E
In vitro phagocytosis

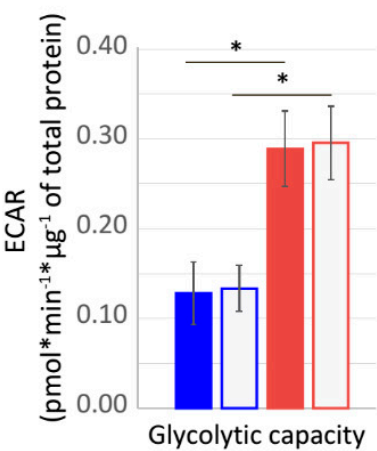

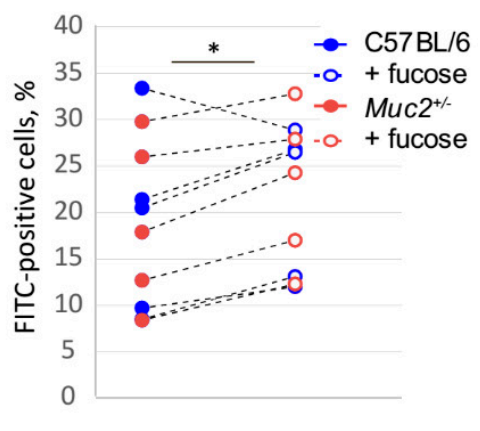

Figure 3. Energy metabolism and phagocytic activity in isolated peritoneal macrophages. (A). OCR was measured at basal level followed by the sequential treatment with oligomycin, FCCP, and a mixture of antimycin A and rotenone. Each data point represents average OCR per group per measurement. (B). Basal respiration, maximal, and reserve respiratory capacity. "C57BL/s" vs. "Muc2 ${ }^{+/-": ~}{ }^{*} p<0.05,{ }^{* *} p<0.01, n=5-6$, Student's $t$-test. (C). ECAR was measured at basal level followed by the sequential treatment with oligomycin, FCCP, and a mixture of antimycin A and rotenone. Each data point represents average ECAR per group per measurement. (D). Glycolytic capacity. "C57BL/s" vs. "Muc2 ${ }^{+/-~ ": ~}{ }^{*} p<0.05$, $n=5-6$, Student's $t$-test. (E). In vitro phagocytosis of peritoneal macrophages, percentage of cells that captured fluorescent particles. "Fucose" vs. "Control": * $p<0.05, \mathrm{~N}=11$ in each group, paired Student's $t$-test.

\subsection{Fucose Affects Reproductive Performance and Macrophage Polarization in BALB/c Mice}

Since fucose affects macrophages directly, this can cause implantation deficiency in $M u c 2^{+/-}$dams. In order to test the opposite effect of fucose on macrophages depending on their initial propensity for polarization, we used two prototypical mouse strains with Th1and Th2-type of the innate immune response: C57BL/6 and BALB/c, respectively. Our experiments revealed that, indeed, fucose strongly reduced reproductive performance in BALB/c dams (Fisher exact test, $p<0.001$, Figure $4 \mathrm{~A}$ ) so that we received no live progeny upon fucose treatment. At the same time, C57BL/ 6 dams demonstrated even higher reproductive performance upon fucose treatment (Fisher exact test, $p<0.001$, Figure 4A). Accordingly, fucose significantly reduced the percentage of M1 peritoneal macrophages at $5 \mathrm{GD}$ in pregnant dams (Mann-Whitney $U$ test: $Z=2.14, p<0.05$, Figure $4 \mathrm{~B}$ ), whereas no such change was observed in BALB/c dams (Figure 4B). In fact, there was a tendency to M1 upregulation upon fucose treatment in BALB/c pregnant dams. Thus, fucose might directly affect macrophage polarization in a predisposed host and affect implantation and pregnancy outcome. 
A Reproductive performance

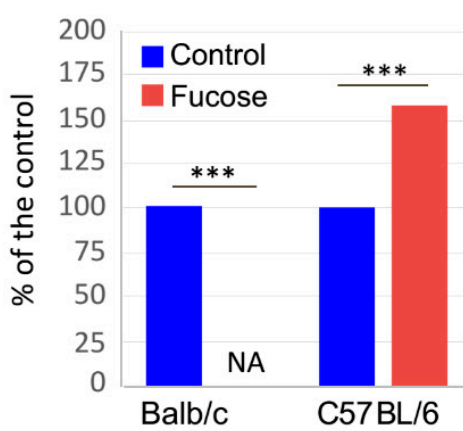

B Macrophage polarization in pregnant dams, $5 \mathrm{GD}$ C57BL/6

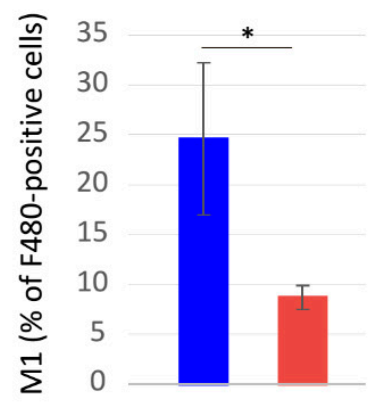

- Control

Fucose

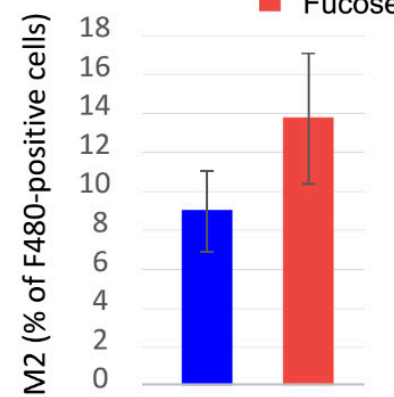

C Macrophage polarization in pregnant dams, $5 \mathrm{GD}$

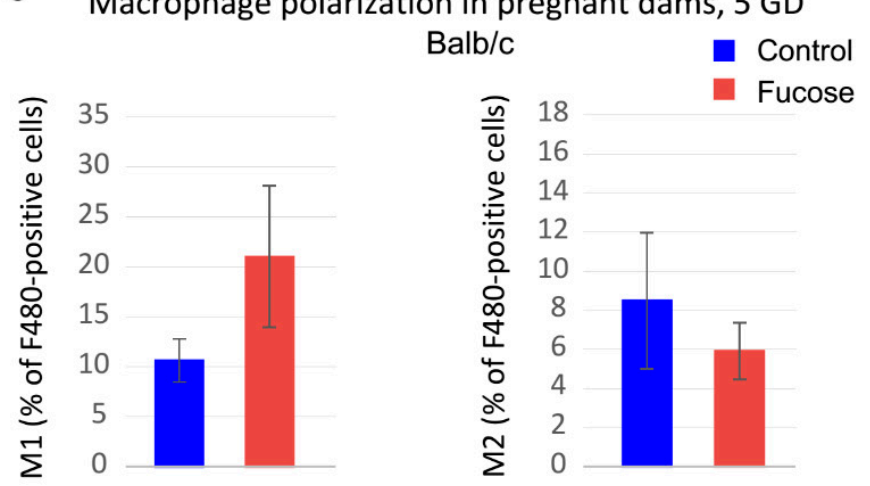

Figure 4. Fucose affects reproductive performance and macrophage polarization in C57BL/6 and BALB/c dams. (A). Reproductive performance in C57BL/ 6 and BALB/c dams upon fucose treatment. ${ }^{* * *} p<0.001$, Fisher exact test; $N($ dams $)=9$ in each group. (B). Percentage of M1 and M2 macrophages upon fucose treatment in pregnant C57BL/6 dams. "Fucose" vs. "Control": * $p<0.05, \mathrm{~N}=3-4$, Mann-Whitney $U$ test. (C). Percentage of M1 and M2 macrophages upon fucose treatment in pregnant BALB/c dams, $\mathrm{N}=3-8$.

\section{Discussion}

Even though fucosylated glycans play a pivotal role in pregnancy [62], not much is known about the effect of free fucose on embryo development and implantation. Given the fact that fucose affected pregnancy and reproductive performance in $\mathrm{Muc}^{+/-}$only, we propose that this effect is not common in wild-type mice, but is associated with Muc2 mutation. Muc2 gene encodes for a major intestinal glycoprotein Mucin 2, which forms a gel-like barrier on the apical surface of the intestinal epithelial cells and protects the mucosal immune system from unwanted contact with the intestinal bacteria [22]. Homozygous mutation in this gene results in an inflammatory response, spontaneous colitis, loss of the intestinal barrier integrity, and development of adenocarcenomas [22,23]. Moreover, mucin depletion and inflammatory reaction cause substantial changes in the intestinal microflora in Muc2 mutant mice [24]. At the same time, $\mathrm{Muc2}^{+/-}$animals appear normal both in terms of general physiology and in the morphology and function of the intestine [59]. However, co-housing of mice with different microbiomes are known to affect intestinal bacterial communities [60], therefore $M u c 2$ mutant mice' microflora partially equilibrated with their otherwise physiologically normal siblings, as was shown by metagenomic analysis. Some crucial beneficial bacteria like Escherichia and Blautia were significantly downregulated upon co-housing with the mutant mice. For instance, Blautia is one of the major butyrate producers in the intestine, and its reduction is associated with Crohn's disease [63,64]. Butyrate, in turn, is known to promote M2 macrophage polarization [65] and is associated with the decrease of pregnancy complications in rat models [66]. Thus, macrophage propensity to polarize might originate from the background immune-system-microflora interactions via the changes in immunity or metabolism. Our in vitro experiments demonstrate that 
macrophages from $\mathrm{Muc}^{+/-}$females are more prone to anaerobic glycolysis, rather than oxidative phosphorylation, compared to C57BL/ 6 (Figure 3), which might provide a favorable metabolic state for M1 polarization under specific circumstances like pregnancy in combination with an external stimulus, like fucose (Figure 2) $[67,68]$. Apparently, fucose is one of the stimuli that can promote macrophage functions depending on their intrinsic properties. In agreement with this hypothesis, the two prototypical mouse strains with Th1- and Th2-type of the innate immune response demonstrated the opposite effect of fucose treatment on pregnancy outcome (Figure 4). This means that such an important process as macrophage polarization during pregnancy might be differentially affected by fucose depending on the immune status of these cells. Thus, macrophage polarization might at least partially explain the opposite effect of fucose on pregnancy in the mouse strains under study.

It was shown previously that inhibition of terminal fucosylation affects the differentiation of M1 macrophages and leads to the resolution of inflammation [69]. Fucose itself has been shown to inhibit macrophage M1 polarization and ameliorated DSS-induced acute colitis [70]. At the same time, in our previous study, fucose improved inflammation neither in acute, nor in chronic DSS-induced colitis [71], which might also be explained by the differences in the baseline microflora and immune system activation in mice at the two animal facilities. At the same time, to our knowledge, there is no data on the effects of fucose on macrophages in vitro. Our experiments demonstrated that macrophages can be directly affected by fucose as it induced phagocytosis in vitro (Figure 3A). Thus far, we do not know whether fucose acts via macrophage membrane receptors or directly interferes with metabolism. This question should further be addressed in order to understand the molecular mechanisms of fucose action on immune cells with a predisposition to Th-1 or Th-2 immune response. Altogether, these findings demonstrate that fucose causes a dramatic reduction in the reproductive performance in mice predisposed to Th2-type immune response or in mice lacking key intestinal commensal bacteria. Thus, fucose, a potentially beneficial molecule, is also a physiologically active compound that might have deleterious effects depending on the immune background and must be used with caution.

\section{Conclusions}

This study shows that intestinal microbiota associated with chronic inflammation in $\mathrm{Muc2}^{+/-}$mice might affect pregnancy outcome when transferred to the otherwise healthy C57BL/ 6 animals. This might be explained, at least in part, by its effect on macrophage polarization and metabolism, as these cells actively participate in implantation and pregnancy progression. At the same time, fucose acts as a differential regulator of macrophage polarization depending on their intrinsic functional and metabolic programs. Thus, fucose exerts opposing effects on pregnancy development in mice with predisposition to Th-1 or Th-2 immune response.

Author Contributions: Formal analysis, E.L.A. and E.N.K.; Funding acquisition, E.L.A., and E.N.K.; Investigation, E.L.A., V.D.B., N.A.F., O.V.G., K.M.A., and E.N.K.; Methodology, E.L.A., and E.N.K.; Supervision, E.L.A., and E.N.K.; Writing—original draft, E.L.A., E.L.A., and E.N.K.; Writing—review \& editing, E.L.A., V.D.B., N.A.F., O.V.G., K.M.A., E.L.A., and E.N.K. All authors have read and agreed to the published version of the manuscript.

Funding: Laboratory animals were obtained with the support of the Governmental projects \# 02592019-0004-C-01 and Budgetary funding for basic scientific research \# 0538-2019-0005. Microflora analysis was supported by the RFBR grant \# 19-015-00169. FC analysis was supported by the Russian Science Foundation (RSF) grant \# 20-64-47020. Mitochondrial respiration was supported by the RSF grant \# 20-74-10022.

Institutional Review Board Statement: The study was conducted according to the guidelines of the Declaration of Helsinki, and approved by the Inter-institutional bioethical committee at ICG SB RAS, protocol \#18.6 (14.10.2013).

Informed Consent Statement: Not applicable. 
Data Availability Statement: The data presented in this study are available on request from the corresponding author.

Conflicts of Interest: The authors declare no conflict of interest. The funders had no role in the design of the study; in the collection, analyses, or interpretation of data; in the writing of the manuscript, or in the decision to publish the results.

\section{References}

1. Hooper, L.V.; Littman, D.R.; Macpherson, A.J. Interactions between the microbiota and the immune system. Science 2012, 336, 1268-1273. [CrossRef] [PubMed]

2. Rescigno, M. Intestinal microbiota and its effects on the immune system. Cell Microbiol. 2014, 16, 1004-1013. [CrossRef]

3. Tomkovich, S.; Jobin, C. Microbiota and host immune responses: A love-hate relationship. Immunology 2016, 147, 1-10. [CrossRef]

4. Nashida, J.; Nishi, N.; Takahashi, Y.; Hayashi, C.; Igarashi, M.; Takahashi, D.; Toshima, K. Systematic and Stereoselective Total Synthesis of Mannosylerythritol Lipids and Evaluation of Their Antibacterial Activity. J. Org. Chem. 2018, 83, 7281-7289. [CrossRef] [PubMed]

5. $\quad$ Robertson, R.C.; Kaliannan, K.; Strain, C.R.; Ross, R.P.; Stanton, C.; Kang, J.X. Maternal omega-3 fatty acids regulate offspring obesity through persistent modulation of gut microbiota. Microbiome 2018, 6, 95. [CrossRef] [PubMed]

6. Burrello, C.; Garavaglia, F.; Cribiu, F.M.; Ercoli, G.; Lopez, G.; Troisi, J.; Colucci, A.; Guglietta, S.; Carloni, S.; Guglielmetti, S.; et al. Therapeutic faecal microbiota transplantation controls intestinal inflammation through IL10 secretion by immune cells. Nat. Commun. 2018, 9, 5184. [CrossRef] [PubMed]

7. Chung, S.Y.; Ravel, J.; Regan, M. Clinical Relevance of Gastrointestinal Microbiota during Pregnancy: A Primer for Nurses. Biol. Res. Nurs. 2018, 20, 84-102. [CrossRef]

8. Etienne-Mesmin, L.; Chassaing, B.; Desvaux, M.; De Paepe, K.; Gresse, R.; Sauvaitre, T.; Forano, E.; de Wiele, T.V.; Schuller, S.; Juge, N.; et al. Experimental models to study intestinal microbes-mucus interactions in health and disease. FEMS Microbiol. Rev. 2019, 43, 457-489. [CrossRef] [PubMed]

9. Rooks, M.G.; Garrett, W.S. Gut microbiota, metabolites and host immunity. Nat. Rev. Immunol. 2016, 16, 341-352. [CrossRef]

10. Moreno, I.; Codoner, F.M.; Vilella, F.; Valbuena, D.; Martinez-Blanch, J.F.; Jimenez-Almazan, J.; Alonso, R.; Alama, P.; Remohi, J.; Pellicer, A.; et al. Evidence that the endometrial microbiota has an effect on implantation success or failure. Am. J. Obstet. Gynecol. 2016, 215, 684-703. [CrossRef]

11. Otsuki, K.; Imai, N. Effects of lactoferrin in 6 patients with refractory bacterial vaginosis. Biochem. Cell Biol. 2017, 95, 31-33. [CrossRef] [PubMed]

12. Amabebe, E.; Anumba, D.O. The Vaginal Microenvironment: The Physiologic Role of Lactobacilli. Front. Med. $2018,5,181$. [CrossRef]

13. Johansson, M.E.; Phillipson, M.; Petersson, J.; Velcich, A.; Holm, L.; Hansson, G.C. The inner of the two Muc2 mucin-dependent mucus layers in colon is devoid of bacteria. Proc. Natl. Acad. Sci. USA 2008, 105, 15064-15069. [CrossRef]

14. Bergstrom, K.S.; Kissoon-Singh, V.; Gibson, D.L.; Ma, C.; Montero, M.; Sham, H.P.; Ryz, N.; Huang, T.; Velcich, A.; Finlay, B.B.; et al. Muc2 protects against lethal infectious colitis by disassociating pathogenic and commensal bacteria from the colonic mucosa. PLoS Pathog. 2010, 6, e1000902. [CrossRef]

15. Linden, S.K.; Florin, T.H.; McGuckin, M.A. Mucin dynamics in intestinal bacterial infection. PLoS ONE 2008, 3, e3952. [CrossRef] [PubMed]

16. Tailford, L.E.; Crost, E.H.; Kavanaugh, D.; Juge, N. Mucin glycan foraging in the human gut microbiome. Front. Genet. 2015,6 , 81. [CrossRef]

17. Reily, C.; Stewart, T.J.; Renfrow, M.B.; Novak, J. Glycosylation in health and disease. Nat. Rev. Nephrol. 2019, 15, 346-366. [CrossRef] [PubMed]

18. Chang, C.S.; Kao, C.Y. Current understanding of the gut microbiota shaping mechanisms. J. Biomed. Sci. 2019, 26, 59. [CrossRef] [PubMed]

19. Lowe, E.; Rice, P.; Ha, T.; Li, C.; Kelley, J.; Ensley, H.; Lopez-Perez, J.; Kalbfleisch, J.; Lowman, D.; Margl, P.; et al. A (1->3)-beta-Dlinked heptasaccharide is the unit ligand for glucan pattern recognition receptors on human monocytes. Microbes Infect. 2001, 3, 789-797. [CrossRef]

20. Nonaka, Y.; Izumo, T.; Izumi, F.; Maekawa, T.; Shibata, H.; Nakano, A.; Kishi, A.; Akatani, K.; Kiso, Y. Antiallergic effects of Lactobacillus pentosus strain S-PT84 mediated by modulation of Th1/Th2 immunobalance and induction of IL-10 production. Int. Arch. Allergy Immunol. 2008, 145, 249-257. [CrossRef]

21. Bergstrom, K.S.; Xia, L. Mucin-type O-glycans and their roles in intestinal homeostasis. Glycobiology 2013, 23, 1026-1037. [CrossRef]

22. Velcich, A.; Yang, W.; Heyer, J.; Fragale, A.; Nicholas, C.; Viani, S.; Kucherlapati, R.; Lipkin, M.; Yang, K.; Augenlicht, L. Colorectal cancer in mice genetically deficient in the mucin Muc2. Science 2002, 295, 1726-1729. [CrossRef]

23. Bao, Y.; Guo, Y.; Li, Z.; Fang, W.; Yang, Y.; Li, X.; Li, Z.; Xiong, B.; Chen, Z.; Wang, J.; et al. MicroRNA profiling in Muc2 knockout mice of colitis-associated cancer model reveals epigenetic alterations during chronic colitis malignant transformation. PLoS ONE 2014, 9, e99132. [CrossRef] 
24. Wu, M.; Wu, Y.; Li, J.; Bao, Y.; Guo, Y.; Yang, W. The Dynamic Changes of Gut Microbiota in Muc2 Deficient Mice. Int. J. Mol. Sci. 2018, 19, 2809. [CrossRef]

25. Van der Sluis, M.; De Koning, B.A.; De Bruijn, A.C.; Velcich, A.; Meijerink, J.P.; Van Goudoever, J.B.; Buller, H.A.; Dekker, J.; Van Seuningen, I.; Renes, I.B.; et al. Muc2-deficient mice spontaneously develop colitis, indicating that MUC2 is critical for colonic protection. Gastroenterology 2006, 131, 117-129. [CrossRef] [PubMed]

26. Kawashima, H. Roles of the gel-forming MUC2 mucin and its O-glycosylation in the protection against colitis and colorectal cancer. Biol. Pharm. Bull. 2012, 35, 1637-1641. [CrossRef] [PubMed]

27. Bergstrom, K.; Liu, X.; Zhao, Y.; Gao, N.; Wu, Q.; Song, K.; Cui, Y.; Li, Y.; McDaniel, J.M.; McGee, S.; et al. Defective Intestinal Mucin-Type O-Glycosylation Causes Spontaneous Colitis-Associated Cancer in Mice. Gastroenterology 2016, 151, 152-164 e111. [CrossRef] [PubMed]

28. Morampudi, V.; Dalwadi, U.; Bhinder, G.; Sham, H.P.; Gill, S.K.; Chan, J.; Bergstrom, K.S.; Huang, T.; Ma, C.; Jacobson, K.; et al. The goblet cell-derived mediator RELM-beta drives spontaneous colitis in Muc2-deficient mice by promoting commensal microbial dysbiosis. Mucosal Immunol. 2016, 9, 1218-1233. [CrossRef]

29. Burger-van Paassen, N.; van der Sluis, M.; Bouma, J.; Korteland-van Male, A.M.; Lu, P.; Van Seuningen, I.; Boehm, G.; van Goudoever, J.B.; Renes, I.B. Colitis development during the suckling-weaning transition in mucin Muc2-deficient mice. Am. J. Physiol. Gastrointest. Liver Physiol. 2011, 301, G667-G678. [CrossRef]

30. Lu, P.; Burger-van Paassen, N.; van der Sluis, M.; Witte-Bouma, J.; Kerckaert, J.-P.; van Goudoever, J.B.; Van Seuningen, I.; Renes, I.B. Colonic gene expression patterns of mucin muc2 knockout mice reveal various phases in colitis development1. Inflammatory Bowel Diseases 2011, 17, 2047-2057. [CrossRef] [PubMed]

31. Morelli, S.; Mandal, M.; Goldsmith, L.; Kashani, B.; Ponzio, N. The maternal immune system during pregnancy and its influence on fetal development. Res. Rep. Biol. 2015, 2015, 171. [CrossRef]

32. Robertson, S.; Petroff, M.; Hunt, J. Immunology of Pregnancy; Academic Press: London, UK, 2015; Volume 2, pp. $1835-1874$.

33. Zhang, Y.; Li, X.; Luo, Z.; Ma, L.; Zhu, S.; Wang, Z.; Wen, J.; Cheng, S.; Gu, W.; Lian, Q.; et al. ECM1 is an essential factor for the determination of M1 macrophage polarization in IBD in response to LPS stimulation. Proc. Natl. Acad. Sci. USA 2020, 117, 3083-3092. [CrossRef]

34. Yang, Y.; Li, L.; Xu, C.; Wang, Y.; Wang, Z.; Chen, M.; Jiang, Z.; Pan, J.; Yang, C.; Li, X.; et al. Cross-talk between the gut microbiota and monocyte-like macrophages mediates an inflammatory response to promote colitis-associated tumourigenesis. Gut $\mathbf{2 0 2 0 .}$ [CrossRef] [PubMed]

35. Jones, G.-R.; Bain, C.C.; Fenton, T.M.; Kelly, A.; Brown, S.L.; Ivens, A.C.; Travis, M.A.; Cook, P.C.; MacDonald, A.S. Dynamics of Colon Monocyte and Macrophage Activation During Colitis. Front. Immunol. 2018, 9. [CrossRef] [PubMed]

36. Steinbach, E.C.; Plevy, S.E. The Role of Macrophages and Dendritic Cells in the Initiation of Inflammation in IBD. Inflamm. Bowel Dis. 2013, 20, 166-175. [CrossRef]

37. Archer, A.C.; Muthukumar, S.P.; Halami, P.M. Anti-inflammatory potential of probiotic Lactobacillus spp. on carrageenan induced paw edema in Wistar rats. Int. J. Biol. Macromol. 2015, 81, 530-537. [CrossRef] [PubMed]

38. Oh, N.S.; Joung, J.Y.; Lee, J.Y.; Kim, Y. Probiotic and anti-inflammatory potential of Lactobacillus rhamnosus 4 B15 and Lactobacillus gasseri 4M13 isolated from infant feces. PLoS ONE 2018, 13, e0192021. [CrossRef]

39. Cleophas, M.C.P.; Ratter, J.M.; Bekkering, S.; Quintin, J.; Schraa, K.; Stroes, E.S.; Netea, M.G.; Joosten, L.A.B. Effects of oral butyrate supplementation on inflammatory potential of circulating peripheral blood mononuclear cells in healthy and obese males. Sci. Rep. 2019, 9, 775. [CrossRef]

40. Canani, R.B.; Costanzo, M.D.; Leone, L.; Pedata, M.; Meli, R.; Calignano, A. Potential beneficial effects of butyrate in intestinal and extraintestinal diseases. World J. Gastroenterol. 2011, 17, 1519-1528. [CrossRef]

41. Thapa, B.; Lee, K. Metabolic influence on macrophage polarization and pathogenesis. BMB Rep. 2019, 52, 360-372. [CrossRef] [PubMed]

42. Stunault, M.I.; Bories, G.; Guinamard, R.R.; Ivanov, S. Metabolism Plays a Key Role during Macrophage Activation. Mediat. Inflamm. 2018, 2018, 2426138. [CrossRef] [PubMed]

43. Mills, E.L.; O'Neill, L.A. Reprogramming mitochondrial metabolism in macrophages as an anti-inflammatory signal. Eur. J. Immunol. 2016, 46, 13-21. [CrossRef]

44. Ivashkiv, L.B. Inflammatory signaling in macrophages: Transitions from acute to tolerant and alternative activation states. Eur. J. Immunol. 2011, 41, 2477-2481. [CrossRef]

45. Vishnyakova, P.; Elchaninov, A.; Fatkhudinov, T.; Sukhikh, G. Role of the Monocyte-Macrophage System in Normal Pregnancy and Preeclampsia. Int. J. Mol. Sci. 2019, 20, 3695. [CrossRef]

46. Hunt, J.S.; Robertson, S.A. Uterine macrophages and environmental programming for pregnancy success. J. Reprod. Immunol. 1996, 32, 1-25. [CrossRef]

47. Zhang, Y.H.; He, M.; Wang, Y.; Liao, A.H. Modulators of the Balance between M1 and M2 Macrophages during Pregnancy. Front. Immunol. 2017, 8, 120. [CrossRef] [PubMed]

48. Hamilton, S.; Oomomian, Y.; Stephen, G.; Shynlova, O.; Tower, C.L.; Garrod, A.; Lye, S.J.; Jones, R.L. Macrophages Infiltrate the Human and Rat Decidua During Term and Preterm Labor: Evidence That Decidual Inflammation Precedes Labor1. Biol. Reprod. 2012, 86. [CrossRef] 
49. Larsson, J.M.H.; Karlsson, H.; Crespo, J.G.; Johansson, M.E.V.; Eklund, L.; Sjövall, H.; Hansson, G.C. Altered O-glycosylation profile of MUC2 mucin occurs in active ulcerative colitis and is associated with increased inflammation. Inflamm. Bowel Dis. 2011, 17, 2299-2307. [CrossRef]

50. Pickard, J.M.; Chervonsky, A.V. Intestinal fucose as a mediator of host-microbe symbiosis. J. Immunol. 2015, 194, 5588-5593. [CrossRef]

51. Haines-Menges, B.L.; Whitaker, W.B.; Lubin, J.B.; Boyd, E.F. Host Sialic Acids: A Delicacy for the Pathogen with Discerning Taste. Microbiol. Spectr. 2015, 3. [CrossRef]

52. Newburg, D.S.; He, Y. Neonatal Gut Microbiota and Human Milk Glycans Cooperate to Attenuate Infection and Inflammation. Clin. Obstet. Gynecol. 2015, 58, 814-826. [CrossRef]

53. Dias, A.M.; Pereira, M.S.; Padrao, N.A.; Alves, I.; Marcos-Pinto, R.; Lago, P.; Pinho, S.S. Glycans as critical regulators of gut immunity in homeostasis and disease. Cell. Immunol. 2018, 333, 9-18. [CrossRef] [PubMed]

54. McKeen, S.; Young, W.; Fraser, K.; Roy, N.C.; McNabb, W.C. Glycan Utilisation and Function in the Microbiome of Weaning Infants. Microorganisms 2019, 7, 190. [CrossRef]

55. Wang, Y.; Xing, M.; Cao, Q.; Ji, A.; Liang, H.; Song, S. Biological Activities of Fucoidan and the Factors Mediating Its Therapeutic Effects: A Review of Recent Studies. Mar. Drugs 2019, 17, 183. [CrossRef] [PubMed]

56. FELASA Working Group on Revision of Guidelines for Health Monitoring of Rodents and Rabbits; Mahler Convenor, M.; Berard, M.; Feinstein, R.; Gallagher, A.; Illgen-Wilcke, B.; Pritchett-Corning, K.; Raspa, M. FELASA recommendations for the health monitoring of mouse, rat, hamster, guinea pig and rabbit colonies in breeding and experimental units. Lab. Anim. 2014, 48, 178-192. [CrossRef]

57. Pecaut, M.J.; Smith, A.L.; Jones, T.A.; Gridley, D.S. Modification of immunologic and hematologic variables by method of $\mathrm{CO}_{2}$ euthanasia. Comp. Med. 2000, 50, 595-602.

58. Stollings, L.M.; Jia, L.J.; Tang, P.; Dou, H.; Lu, B.; Xu, Y. Immune Modulation by Volatile Anesthetics. Anesthesiology 2016, 125, 399-411. [CrossRef] [PubMed]

59. Cobo, E.R.; Kissoon-Singh, V.; Moreau, F.; Chadee, K. Colonic MUC2 mucin regulates the expression and antimicrobial activity of beta-defensin 2. Mucosal Immunol. 2015, 8, 1360-1372. [CrossRef]

60. Ridaura, V.K.; Faith, J.J.; Rey, F.E.; Cheng, J.; Duncan, A.E.; Kau, A.L.; Griffin, N.W.; Lombard, V.; Henrissat, B.; Bain, J.R.; et al. Gut microbiota from twins discordant for obesity modulate metabolism in mice. Science 2013, 341, 1241214. [CrossRef] [PubMed]

61. Negishi, Y.; Takahashi, H.; Kuwabara, Y.; Takeshita, T. Innate immune cells in reproduction. J. Obstet. Gynaecol. Res. 2018, 44, 2025-2036. [CrossRef]

62. Aplin, J.D.; Jones, C.J. Fucose, placental evolution and the glycocode. Glycobiology 2012, 22, 470-478. [CrossRef]

63. Louis, P.; Flint, H.J. Formation of propionate and butyrate by the human colonic microbiota. Environ. Microbiol. 2017, 19, 29-41. [CrossRef]

64. Takahashi, K.; Nishida, A.; Fujimoto, T.; Fujii, M.; Shioya, M.; Imaeda, H.; Inatomi, O.; Bamba, S.; Sugimoto, M.; Andoh, A. Reduced Abundance of Butyrate-Producing Bacteria Species in the Fecal Microbial Community in Crohn's Disease. Digestion 2016, 93, 59-65. [CrossRef]

65. Ji, J.; Shu, D.; Zheng, M.; Wang, J.; Luo, C.; Wang, Y.; Guo, F.; Zou, X.; Lv, X.; Li, Y.; et al. Microbial metabolite butyrate facilitates M2 macrophage polarization and function. Sci. Rep. 2016, 6, 24838. [CrossRef]

66. Chang, Y.; Chen, Y.; Zhou, Q.; Wang, C.; Chen, L.; Di, W.; Zhang, Y. Short-chain fatty acids accompanying changes in the gut microbiome contribute to the development of hypertension in patients with preeclampsia. Clin. Sci. 2020, 134, 289-302. [CrossRef] [PubMed]

67. Sadiku, P.; Walmsley, S.R. Hypoxia and the regulation of myeloid cell metabolic imprinting: Consequences for the inflammatory response. EMBO Rep. 2019, 20. [CrossRef]

68. Van den Bossche, J.; Baardman, J.; Otto, N.A.; van der Velden, S.; Neele, A.E.; van den Berg, S.M.; Luque-Martin, R.; Chen, H.J.; Boshuizen, M.C.; Ahmed, M.; et al. Mitochondrial Dysfunction Prevents Repolarization of Inflammatory Macrophages. Cell Rep. 2016, 17, 684-696. [CrossRef] [PubMed]

69. Li, J.; Hsu, H.C.; Ding, Y.; Li, H.; Wu, Q.; Yang, P.; Luo, B.; Rowse, A.L.; Spalding, D.M.; Bridges, S.L., Jr.; et al. Inhibition of fucosylation reshapes inflammatory macrophages and suppresses type II collagen-induced arthritis. Arthritis Rheumatol. 2014, 66, 2368-2379. [CrossRef]

70. He, R.; Li, Y.; Han, C.; Lin, R.; Qian, W.; Hou, X. L-Fucose ameliorates DSS-induced acute colitis via inhibiting macrophage M1 polarization and inhibiting NLRP3 inflammasome and NF-kB activation. Int. Immunopharmacol. 2019, 73, 379-388. [CrossRef]

71. Borisova, M.A.; Snytnikova, O.A.; Litvinova, E.A.; Achasova, K.M.; Babochkina, T.I.; Pindyurin, A.V.; Tsentalovich, Y.P.; Kozhevnikova, E.N. Fucose Ameliorates Tryptophan Metabolism and Behavioral Abnormalities in a Mouse Model of Chronic Colitis. Nutrients 2020, 12, 445. [CrossRef] [PubMed] 